\title{
An Educational Perspective is As An Analysis Method of Facial Expressions on Joking Internet at the Social Media
}

\author{
Ferri Susanto \\ ${ }^{1}$ Faculty of Shariah, IAIN Bengkulu, Bengkulu, Indonesia \\ e-mail: ferialfa02@gmail.com \\ \#Corresponding Author \\ Whatsapp Number $\{+62-81367531983\}$
}

\section{ARTICLE HISTORY}

Received: 22 March 2019

Revised: 18 April 2019

Accepted: 23 June 2019

Copyright @ 2019 Authors \& Published by IIES Independent. This is an open-access article distributed under the terms of the CC-BY-SA License.

\section{ABSTRACT}

The title of this research is An educational perspective is an Analysis of Facial Expressions on Joking Internet at the Social Media. The objective of this research was the Analysis of Facial Expressions, that involves : "Derp Face", "Derpina Face", "Troll Face", "Fuuuu Face", "Forever Alone", "LOL Face", "Me Gusta Face", "Okay Face", and "Poker Face" the limited on the research only took the Data Febuary 2017. The design of this research was descriptive research. This method used to get the description about facial expressions by analyzing, interpreting and concluding. After that the researcher analyzed the data, so the researcher concluded that the Analysis of Facial Expressions on Internet such as: 1)“Derp Face" indicating neutral expression, 2)"Derpina Face" indicating neutral expression, 3) "Troll Face" indicating feel glad, 4) "Fuuuu Face" indicated that someone feels angry, 5)"Forever Alone" indicated that someone feels sad, and Alone, 6)"LOL Face" indicated that someone feels glad, 7)"Me Gusta" indicated that someone feels like, 8) "Okay Face" indicated someone feels sad, 9)"Poker Face" indicated that someone feels no specific emotion. And the last, the researcher suggested that the study about semiotics is supposed to give understanding and knowledge about signs. The results of this research could be as a reference about how to analysis facial expressions could analysis by eyebrows, forehead, eyes, nose, cheeks and skin. This research is also supposed to be a reference for the next researcher as well.

Keywords: Facial Expression; Internet Jokes; Social Media

How to Cite: Susanto, F. (2019). An educational perspective is as an analysis method of Facial Expressions on Joking Internet at the Social Media. International Journal of Advances in Social and Economics, 1(1), 28-35.

\section{Introduction}

Technology is a power that able to change our life style, critical, constructive thinking and way of life. They are like something mechanical system that develop progressively. The real correlation of technology will give the fact relation from a philosophical perspective internet, learning by internet can be discussed under the heading of epistemology, which refers to the study of the origin, nature, limits, and methods of knowledge .How can we know? How can we learn something new from the internet? What is the source of knowledge that we can get from the internet? The complexity of how humans learn is illustrated in this media social. Two positions on internet system are the origin of knowledge and its rel- ationship to the environment are rationalism system and empiricism. These positions are recognizable in current learning theories. Social media is as rational views of human knowledge, can be ideas by reasoning or thinking about what they know. From the Internet that People know ideas about the world, and they learn (discover) these ideas by reflecting upon them.

Developing technology of the world especial for the internet has many impacts for every human being either thinking style or surviving in their life because of it, wherever human live, they really need much information about many things so that they will get it especially from media social by via Internet. Social 
media on internet become more popular day by day and it is used by children, teenager, adult and even the old people in the world. Everybody is familiar, what are 1) Collaborative project such as Wikipedia, 2) Blogs and Micro Blog such as Twitter, 3) Social News networking sites such as Dig and leakernet, 4) Content communities such as YouTube and Daily motion, 5) Social Networking sites such as Face Book, 6) Virtual game words such as world of War Craff, and 7) Virtual social world such as Second life. Burges, C. (2016) stated that social media consists of various user-driven (inbound marketing) channels (e.g., Face Book, twitter, blogs, YouTube) these channels represent a stark difference from the advertiser-driven (outbound marketing) push model. We know that social media is today's most transparent, engaging and interactive form public relations. The facial expressions are the signs of various comical on joking internet of facial human beings that particularly found in social media and its expression make for some comical story on internet.

The entertainment of Social media on internet, sites contain jokes began to emerge that increasingly popular today in social media like posted in gag.com, Trollfootball.com, Twitter, and Face Book. According to survey in the Internet; there are more less 25 Internet jokes use facial expression in gag.com and some of the internet jokes used facial expressions in Face Book and Twitter and even Facial expression on internet jokes becomes a 'trendsetter' in social media. The Internet users can enjoy with some display short funny story on the pictures where the creator tried to make and share a funny story to the users. The facial expression itself has different face likes: "Poker Face", "Fuиuи Face", "Forever Alone", " LOL", "Me Gusta", "Okay Face", "Troll Face,"Derp and Derpina Face”, and others. Behind this it has certain function and often appear exclusively to give comment about a picture. In getting the meaning of facial expression, it should be used semiotic analysis.

Barthes, R, (1988) stated that semiotics or semiology, discipline deriving from the American logician, as a formal system of signs, it means that the relation of words to things is not natural but conventional; thus a language is essential a self contained system of signs wherein each element is meaningless by itself and meaningful only by its differentiation from the other elements. Nummenmaa (1964) and Leonhard (1976) (cited in Nöth:1995) "the variable semiotic potential of the face is usually studied under the heading facial expression, for example: eyebrow and forehead, lips and jaw, cheeks and skin are the region by which facial signals can be transmitted". The explanation above can be concluded that facial expression on internet jokes should be analysis in semiotic analysis.

Based on phenomena above, the researcher interests to investigate facial expressions on internet jokes so that researcher decides to have a research entitled "An educational perspective is as an analysis method of Facial Expressions on Joking Internet at the Social Media”.

\section{Methods}

This research is conducted by using descriptive qualitative method, which tried to describe of Facial Expressions on the internet jokes at the social media in order to get description about them. This method reffers to the actual problem or condition. According to Maxwell (1996:17) the strength of qualitative research designed derive primarily from its inductive approach, its focus on specific situation or people, and its emphasis on words rather than numbers. Therefore, the researcher used the descriptive qualitative method because the researcher analyze of Facial expressions on internet jokes at social media.

The research objects are facial expressions at the social media on internet only describe the meanings and functions of Facial expressions and the data were taken from social media on the internet. The main instruments that are used by the researcher are : Notebook, Modem, data analysis forms, picture of facial expressions, meanings and functions. The data Collection technique, The researcher will collect the data as below:

Data were social media describe the meanings and functions of Facial expressions and they were taken from social media on internet 2017 and then select the pictures of facial expression of "Troll Face", "Rage Face", Me Gusta", Okay Face", "Forever Alone", "LOL", "Derp and Derpina Face" And the last "Poker Face". The data analyzing technique, The researcher will analyze the data, as follows: The researcher makes a group of facial expressions one by one, The researcher was analyzed the meanings and functions of facial expressions that use theory Nummenmaa (1964) and Leonhard (1976) (cited in Noth: 1995), Describe and interpret, make the conclusions are based the semiotics analysis.

\section{Results and Discussion}

The data were taken from the social media on internet. There were many Facial Expressions that were found on Internet joke at the social media which use "Derp 
Face", "Derpina Face", "Troll face”, "fuиuиu face”, "Forever Alone", "LOL Face", "Me Gusta", "Okay Face" and "Poker Face" Generally, the result of this research showed that the meaning and function of facial expressions on internet jokes at the social media. The researcher assumed that there are many ways to convey a message at the social media such as words, pictures and signs. "A new one is facial expression". As long as the viewer can understand what are the meanings and functions of each facial expression well, so she or he can interpret and understand what the face means that produced by each facial expressions.

\section{The Meaning of Facial Expression on internet jokes in Social Media}

There were many Facial Expressions that found on Internet which use "Derp Face", "Derpina Face", "Troll face", "fиииии face", "Forever Alone", "LOL", "Me
Gusta", "Okay Face" and "Poker Face" And then make a group for each facial expression 1) "Derp Face" there are five face, 2) "Derpina Face" there are seven face, 3) "Troll face" there are two face, 4) "Fuuuu Face" there are two face, 5) "Forever Alone" there are one face, 6) "LOL" Face there are two face, 7) "Me Gusta" there are one face, 8) "Okay Face" there are two face, 9) "Poker Face". And then find out the meaning as below:

- Derp Face". There are five of "Derp face" used on the pictures on internet jokes in social media. These facial expressions are based on Nummenmaa and Leonhard theory of variable semiotics potential of the face is usually studied under the heading facial expression can be analysis as eyebrows and forehead, eyes, nose, lips and jaw, cheeks and skin are the regions by which facial signals can be transmitted.

Table 1. The Meaning of Facial Expressions "Derp Face"

\begin{tabular}{|l|l|l|}
\hline No & Facial expressions & \multicolumn{1}{c}{ Meanings } \\
\hline 1 & $\begin{array}{l}\text { a. The eyes which are only illustrated by two dots and rounded without eyebrows or lines around the eyes } \\
\text { indicating a very plain gaze, no specific emotion reflected from the eyes. The absence of eyebrows and } \\
\text { lines that usually emphasizing the gaze of the eyes also indicating no specific emotion is reflected from } \\
\text { the eyes. } \\
\text { One curved downward line under the eyes as mouth signifying a close mouth with small smile. This } \\
\text { indicating someone who gives neutral expression. With someone statement or argument with him. }\end{array}$ \\
\hline 2 & $\begin{array}{l}\text { Looking up eyes and eyebrows showing angry and disappointed feeling. Pursed lips and no lines around the } \\
\text { lips it indicating a sad, angry, disappointed expression. it indicates that someone who cannot say anything } \\
\text { just keep silent. Because she or he surprised with someone said with she or he }\end{array}$ \\
\hline 5 & $\begin{array}{l}\text { Looking-up eyes and eyebrows showing a surprise feeling.one dot under the eyes as mouth signifying a } \\
\text { closed mouth with no smile or frown, just tighly closed. This indicating someone who cannot say anything } \\
\text { tired and sleppy. With someone say with he or she. }\end{array}$ \\
\hline
\end{tabular}

In all expression of "Derp Face" above it can be concluded that expression from "Derp Face" it is showing neutral expression, happy and sometimes just be a good listening.

- "Derpina Face". There are eight of "Derpina face" used on the pictures on internet jokes in social media. These facial expression based on Nummenmaa and Leonhard theory the potential variable semiotics of the face is usually studied under the heading facial expression can be analysis as eyebrows and forehead, eyes, nose, lips and jaw, cheeks and skin are the regions by which facial signals can be transmitted.

Table 2. The Meaning of Facial Expression "Derpina Face"

\begin{tabular}{|c|l|l|}
\hline No & Facial expression & \multicolumn{1}{c|}{ Meaning } \\
\hline 1 & $\begin{array}{l}\text { The eyes which are only illustrated by two dots with line around the eyes as eyelash,curved line around the } \\
\text { eyes and eyebrows indicating a dazed gaze, think something is specific emotion reflected from the } \\
\text { eyes.small rounded under the eyes as mouth signifying a open mouth with no smile and frown. This } \\
\text { indicating someone who feel dazed in some situation, she or he not understand or confuse with someone } \\
\text { else statement. }\end{array}$ \\
\hline 2 & $\begin{array}{l}\text { The eyes which are only illustrated by two dots with line around the eyes as eyelash and eyebrows } \\
\text { indicating a very plain gaze, think something is specific emotion reflected from the eyes.square under the } \\
\text { eyes as mouth and that some line in mouth as a tooth signifying open the mouth with no smile or frown. } \\
\text { This indicating someone who think and hope something }\end{array}$ \\
\hline
\end{tabular}




\begin{tabular}{|c|c|c|}
\hline 3 & & $\begin{array}{l}\text { The eyes are only illustrated by chynical gaze.Smile up with some line around it indicating some one feel } \\
\text { happy if somebody feel bad situation. }\end{array}$ \\
\hline 4 & & $\begin{array}{l}\text { The eyes which are only illustrated by two dots with line around the eyes as eyelash and without eyebrows } \\
\text { indicating a very plain gaze, delusional is specific emotion reflected from the eyes. line of triangle under the } \\
\text { eyes as mouth and that some line in mouth as a tooth signifying open the mouth with smile. This } \\
\text { indicating someone who feel happy and hope something with her. }\end{array}$ \\
\hline 5 & & $\begin{array}{l}\text { Looking up eyes and up eyebrows with full make up this indicating she is tease, and confidence feeling. } \\
\text { One straight horizontal line under the eyes as mouth use lipstick and one shorter horizontal line under the } \\
\text { mouth signifying a tighly closed. This indicating someone who cannot say anything just keep silent. }\end{array}$ \\
\hline 6 & & $\begin{array}{l}\text { The eyes which are only illustrated by two dots and rounded without eyebrows or lines around the eyes } \\
\text { indicating a very plain gaze, no specific emotion reflected from the eyes. The absence of eyebrows and } \\
\text { lines that usually emphasizing the gaze of the eyes also indicating no specific emotion is reflected from the } \\
\text { eyes.one curved downward line under the eyes as mouth signifying a close mouth with no smile . this } \\
\text { indicating someone who give neutral expression. }\end{array}$ \\
\hline 7 & & $\begin{array}{l}\text { The yes only is illustrated by line without eyebrows showing happy feeling.Curved lines indicating smile } \\
\text { or happy expression. This is indicating someone who feel happy for something or someone. }\end{array}$ \\
\hline 8 & & $\begin{array}{l}\text { The eyes which are only illustrated by two small dots and rounded without eyebrows or lines around the } \\
\text { eyes indicating a simple gaze from the eyes.one curved line under the eyes as mouth with a simple smile. } \\
\text { This indicating someone who feel happy or neutral for something and some situation. }\end{array}$ \\
\hline
\end{tabular}

All of expression of "Derpina Face" above it can be concluded that expression from "Derpina Face" it is showing neutral expression, happy, hope for someone or thing and sometime expression of tease :

- "Troll Face". There are three of "Troll face" used on the pictures on internet jokes in social media. These facial expressions based on Nummenmaa and Leonhard theory the variable semiotics potential of the face is usually studied under the heading facial expression can be analysis as eyebrows and forehead, eyes, nose, lips and jaw, cheeks and skin are the regions by which facial signals can be transmitted.

Table 3. The Meaning of Facial Expression "Troll Face"

\begin{tabular}{|c|l|l|}
\hline No & Facial expression & \multicolumn{1}{c|}{ Meaning } \\
\hline 1 & $\begin{array}{l}\text { The eyes which are only illustrated cynical gaze and eyebrows, and there is line around the eyes. Showing a } \\
\text { happy or tease somebody because she or he have a winner in a some situation. With Big smile this indicating } \\
\text { someone who feel very happy, satisfied with interlocutor. }\end{array}$ \\
\hline 2 & $\begin{array}{l}\text { The eyes which are only illustrated cynical gaze and eyebrows, and there is line earound the eyes. Showing } \\
\text { a happy or tease somebody because she or he have a winner in a some situation. With Big smile this } \\
\text { indicating that someone who feels very happy, satisfied with interlocutor. }\end{array}$ \\
\hline 3 & $\begin{array}{l}\text { The eyes which are only illustrated cynical gaze and eyebrows, and there is line earound the eyes. Showing } \\
\text { a happy or tease somebody because she or he have a winner in a some situation. With Big smile this } \\
\text { indicating someone who feel very happy, satisfied with interlocutor }\end{array}$ \\
\hline
\end{tabular}

- In all expression of "Troll Face" above it can be concluded that expression from "Troll Face" it shows someone who feels glad when they are can became a winner for some situations. "Fuuuu Face". There are two of "Fuuuu face" used on the pictures on internet jokes in social media. These facial expressions based on Numenmaa and Leonhard theory in the variable semiotics potential of the face is usually studied under the heading facial expressions can be analyzed as eyebrows and forehead, eyes, nose, lips and jaw, cheeks and skin are the regions by which facial signals can be transmitted

Table 4.The Meaning of Facial Expression "Fuuuu Face"

\begin{tabular}{|c|l|l|}
\hline No & Facial expression & \multicolumn{1}{c|}{ Function } \\
\hline 1 & $\begin{array}{l}\text { Looking up eyes, and eyebrows show that angry feeling.line of triangle under the eyes as mouth and that } \\
\text { some line in mouth as a tooth signifying open the mouth with no smile. This indicating someone who feels } \\
\text { angry, tired, with somebody or thing. }\end{array}$ \\
\hline 2 & $\begin{array}{l}\text { The eyes which are only illustrated by two dots with up eyebrows and these are lines in forehead around } \\
\text { the eyes indicating a very plain gaze, specific emotion reflected from the eyes is angry emotion. Up } \\
\text { eyebrows and lines that usually emphasizing the gaze of the eyes also indicating specific emotion is reflected } \\
\text { from the eyes. Triangle under the eyes as a sharp teeth and separate between mouth this indicating someone } \\
\text { fuusu } \\
\text { wusuu } \\
\text { who has bad emotion or bad purpose to someone. }\end{array}$ \\
\hline
\end{tabular}

In all expression of "Fuии Face" above it can be concluded that expression from "Fuиии Face" it is showing indicating someone who feesl angry, disappointed with someone or thing. 
- Forever Alone." There is just one of "Forever Alone face" used on the pictures on internet jokes in social media. These facial expressions based on Nummenmaa and Leonhard theory the variable semiotics potential of the face is usually studied under the heading facial expressions can be analyzed as eyebrows and forehead, eyes, nose, lips and jaw, cheeks and skin are the regions by which facial signals can be transmitted.

Table 5. The Meaning of Facial Expression "Forever Alone Face"

\begin{tabular}{|c|l|l|}
\hline No & Facial expression & \multicolumn{1}{c|}{ Meaning } \\
\hline 1 & forever ares are only illustrated by two dots without eyebrows but these are lines around the eyes indicating \\
a very plain gaze with sad is specific emotion reflected from the eyes. one curved downward line under \\
the nose as mouth signifying a close mouth with no smile . this indicating someone who gives sad \\
expression.
\end{tabular}

In all expression of "Forever Alone Face" above it can be concluded that expression from "Forever Alone Face" it is showing someone who feel sad, and Alone without someone or thing

- "LOL Face". There is two of "LOL face" used on the pictures on internet jokes in social media. These facial expression based on Nummenmaa and Leonhard theory the variable semiotics potential of the face is usually studied under the heading facial expression can be analysis as eyebrows and forehead, eyes, nose, lips and jaw, cheeks and skin are the regions by which facial signals can be transmitted.

Table 6. The Meaning of Facial Expression "LOL Face"

\begin{tabular}{|l|l|l|}
\hline NO & Facial expression & Meaning \\
\hline 1 & $\begin{array}{l}\text { Looking up with curved eyebrows and line around the face indicating a tease expression or happy } \\
\text { expression. One curved line and dots as a mouth and teeth signifying a close mouth with a smile this } \\
\text { indicating someone who feels glad very glad until don't open the mouth }\end{array}$ \\
\hline 2 & $\begin{array}{l}\text { The big eyes and eyebrows with line around the face indicating a very plain gaze, and indicating satisfied } \\
\text { expressions.the big mouth as big laugh signyfying loud of laugh. This indicating someone who feels glad } \\
\text { and with loud of laugh for somebody with she or he. }\end{array}$
\end{tabular}

In all expressions of "LOL Face" above it can be concluded that expressions from "LOL Face" it shows someone who feel glad and loud of laugh for somebody mistakes

- "Me Gusta",There is just one of "Me Gusta face" used on the pictures on internet jokes in social media. These facial expressions are based on Nummenmaa and Leonhard theory the variable semiotics potential of the face is usually studied under the heading facial expression can be analysis as eyebrows and forehead, eyes, nose, lips and jaw, cheeks, skin and regions by which facial signals can be transmitted.

\begin{tabular}{|c|c|c|c|}
\multicolumn{2}{l}{ Table 7. The Meaning of Facial Expression "Me Gusta Face" } \\
\hline No & Facial expression & \multicolumn{1}{c|}{ Meaning } \\
\hline 1 & $\begin{array}{l}\text { The big eyes with line around the face indicating a very plain gaze with no specific emotion. With closed } \\
\text { mouth signifying someone not say just keep silent. From the name "Me Gusta", in English is I Like, this } \\
\text { indicating someone who likes something. }\end{array}$ \\
\hline
\end{tabular}

In all expression of "Me Gusta Face" above it can be concluded that expression from "Me Gusta Face" it is showing someone who feels like someone or thing

- Okay Face". There are three of "Okay face" used on the pictures on internet jokes at the social media. These facial expressions based on Nummenmaa and "Leonhard theory the variable semiotics potential of the face is usually studied under the heading facial expressions can be analyzed as eyebrows and forehead, eyes, nose, lips and jaws, cheeks and skins are the regions by which facial signals can be transmitted.

Table 8. The Meaning of Facial Expression "Okay Face"

\begin{tabular}{|c|c|}
\hline Facial expression & Meaning \\
\hline & $\begin{array}{l}\text { Looking-down eyes with downed eyebrows showing a sad or tired feeling. frowing lips with some lines } \\
\text { around it indicates a sad expression. Lines that appear around the lips and forehead indicating a tired, sad, } \\
\text { and old person.the name of the facial expression is "Okay". "Okay" is same with "OK" in English spoken } \\
\text { word. According to Oxpord Dictionary, "Okay: is an exclamination word means 'yes' or 'all right' and } \\
\text { can be used to stop people arguing with your critizing you. This name indicates that are the expression is } \\
\text { for a person who is sad because he/she was forced to accept something in order to stop the critic or } \\
\text { argument from someone. }\end{array}$ \\
\hline
\end{tabular}




\begin{tabular}{|l|l|}
\hline & $\begin{array}{l}\text { Looking-down eyes with downed eyebrows showing a sad or tired feeling.frowing lips with some lines } \\
\text { around it indicating a sad expression. Lines that appear around the lips and forehead indicating a tired, sad, } \\
\text { and old person. }\end{array}$ \\
\hline $\begin{array}{l}\text { Looking - down eyes with downed eyebrows showing a sad or tired feeling.Frowing lips and no some } \\
\text { lines around it indicating a sad expression. Frowing lips and looking down eyes with downed eyebrows } \\
\text { this is indicating someone who feel sad, disappointed person, because she or he become a luzer. }\end{array}$
\end{tabular}

All of expression of "Okay Face" above it can be concluded that expression from "Okay Face" it is showing someone who feel sad, disappointed, and old person.

- "Poker Face". There are two of "Poker face" used on the pictures on internet jokes in social media. These facial expressions are based on Nummenmaa and Leonhard theory the variable semiotics potential of the face is usually studied under the heading facial expressions can be analyzed as eyebrows and foreheads, eyes, nose, lips and jaw, cheeks, skin and regions by which facial signals can be transmitted

Table 9. The Meaning of Facial Expressions "Poker Face"

\begin{tabular}{|c|l|l|}
\hline No & Facial expression & Meaning \\
\hline 1 & $\begin{array}{l}\text { The eyes which are only by two dots without eyebrows or line around the eyes indicating a very plain } \\
\text { gaze, no specific emotion reflected from the eyes. The absence of eyebrows and lines that usually } \\
\text { emphasizing the gaze of the eyes also indicating no specific emotion is reflected from the eyes. One } \\
\text { straight line under the eyes as mouth and one shorter line the mouth signifying a tighly closed mouth } \\
\text { with no smile or frown, just tighly closed. This indicating someone who cannot say anything and just } \\
\text { keep smile because she or he cannot great something. }\end{array}$ \\
\hline $\begin{array}{l}\text { The eyes which are only by two dots flat lines as eyebrows indicating a very plain gaze, no specific } \\
\text { emotion reflected from the eyes. The eyebrows and lines that usually emphasizing the gaze of the eyes } \\
\text { also indicating no specific emotion is reflected from the eyes. One straight line under the eyes as mouth } \\
\text { and the mouth signifying a tighly closed mouth with no smile or frown, just tighly closed. This indicating } \\
\text { someone who cannot say anything and just keep smile because she or he cannot great something. }\end{array}$
\end{tabular}

In all expressions of "Poker Face" above it can be concluded that expression from "Poker Face" it is showing someone who feel no specific emotion just keep silent

The Functions of each Facial Expression when they are post on Internet at the Social media :In social media on internet there were many Facial Expressions found on Internet joke in social media that have different functions to convey a messages:

“Derp Face” : : To convey a message a neutral expression from male

"Derpina Face": To convey a messages a neutral, hope someone or expression offemale blonde. "Troll face" $\quad \begin{aligned} & \text { : to convey a message very glad } \\ & \text { expression }\end{aligned}$

"Fuuuuu face" : to convey a messages Angry and disappointed expression

"Forever Alone": to convey a messages sad, and forever alone expression.

"LOL face" : to convey a messages glad, and loud of laugh expression

"Me Gusta" : to convey a message love, like, expression

"Okay Face" : to convey a messages sad, disappointed expression
"Poker Face" : to convey a message flat expression.

Facial expressions on internet, In fact from the findings above, there were many Facial Expression found on Internet which using "Derp Face", "Derpina Face", "Troll face", "fuиuиu face", "Forever Alone", "LOL", "Me Gusta", "Okay Face" and "Poker Face" that each facial expressions certainly have different meaning and function to convey a message when they are post on internet, sometime the viewer still have problems of Facial expressions including that the meanings and functions. According to Nummenmaa (1964) and Leonhard (1976) (cited in Noth: 1995), the variable semiotic potential of the face is usually studied under the heading facial expressions. Eyebrows and forehead, eyes, nose, lips and jaws, cheeks, and skins are the regions by which facial signals can be transmitted. The fact above showed that view problems still didn't know about meaning and function of facial expression. All of the problems above can be described as follows:

1. The meaning of "Derp Face" is expression from male indicating someone who feels neutral expression, and then the function of "Derp Face" is to convey a messages from male neutral expression and "Derpina Face" is expression from female blonde hair indicating someone who feels neutral, 
dazed, and hopes expression and then the function of "Derpina Face" is to convey a messages from female blonde hair neutral, and 'tease' expression. The meaning of "Troll Face" is expression from male indicating someone who feels like to troll somebody else. And then the function of "troll face" is to convey a message from male glad expression.The meaning of "Fuuuu Face" is expression from male indicating someone who feels angry, disappointed expression. And then the function of "troll face" is to convey a messages angry expression with say "fuuuuu". The meaning of "forever alone face" is expression from male indicates someone who feels sad, disappointed expression. And then the function of "forever alone face" is to convey a messages someone who always alone and single. The meaning of "LOL face" is expression from male indicates that someone who feels glad with laugh of loud. And then the function of "LOL face" is to convey a messages that someone likes tease his friends with Laugh of Loud. The meaning of "Me Gusta" is expression from male indicating someone who feels like someone or thing because from "Me Gusta" is from Spanish and English "I Like". Me Gusta" is to convey a message that someone likes a body or thing. Okay Face" is expression from male indicates someone who feels sad, old person and accept from someone else. The function of "okay face" is to convey a message of patient expression. The meaning of "poker face" is expression from male indicates that someone who feels no specific emotion, keep silent expression. Poker face" is to convey a message from male with no specific emotion just keep silent.

\section{Conclusions}

Based on research results and discussions about the facial expressions at the social media, can be concluded: a) "Derp Face" that face illustrated by not a full circle and crossed eyes to show and convey a message neutral expression from male, b) Derpina Face" that face is illustrated by not a full circle but "derpina" has hair and crossed eyes like "derp" to show and convey a message neutral expressions from female, c) Troll Face" that face illustrated by full circle and big smile to show and convey a message happy or tease someone expression, d) Fuuuu Face" illustrated by not a full circle but sometime there are expressions of full face ,and sharp teeth to show and convey a message angry expression, e) Forever Alone Face" is illustrated by circle not perfect and there are some lines around the face to show and convey a message sad, and alone without somebody or thing expressions, f) LOL Face" is illustrated by full circle and sometimes not full with over Laugh to show and convey a message Very glad, do laughing for someone expression, g) Me Gusta Face" is illustrated by full circle with bulging eyes to show and convey a message likes somebody or thing expression, h) Okay Face" that face is illustrated by full face, there is some lines around the face indicated old person with downed eyebrows to showing and convey a messages sad, and just accept expression, i) of "Poker Face" that face is illustrated by full circle with horizontal line as the mouth to show and convey a messages no specific emotion, just keeps silent expression. Based on the previous chapter, the researcher likes to give the following suggestions: The researcher is supposed to know what are the meanings and functions of facial expressions on internet at the social media. Introduce systematic of semiotic analysis in semantics. The researcher tries to use semiotics analysis that is viewed as an educational perspective for developing semantics. So it hopes that, the next researcher can get the complete results and it also supposed to be reference for the next researcher as well.

\section{References}

Baldwin .T and Bond, F. (2003). Learning the countability of English nouns from corpus data. In Proc. Of the $41^{\text {st }}$ Annual Meeting of the ACL.

Blackmore, Susan. (2000). The Power of Memes . Scientific American, Inc.

Chandler, Daniel. (2001). Semiotics for Beginners. Downloaded in 2014/6/7,

Danesi, Marcel.2004. Messages, Signs, and Meanings: A Basic Textbook in Semiotics and Communication Theory, $3^{\text {rd }}$ Edition. Canadian Scholars' Press Inc.

Dawkins, Richard. (1989). The Selfish Gene (2 ed.), London: Oxford University Press

Folley, William A. (1997). Anthropological Linguistics; An Introduction. Sidney; Blackwell Publisher

Fitriani,Linda. 2010. A Semiotics Analysis of Logo used in Automobile; Universitas Muhammadiyah Surakarta

Hornby, A.S. (2005). Oxford Advanced Learner's Dictionary; $7^{\text {th }}$ Edition. London: Oxford University Press

Hurford. James R, Brandan Heasley, and Michael B Smith. Semantics a Coursebook; $2^{\text {nd }}$ edition: Cambridge.

Leech, Geoffrey. (1981). Semantics: The Study of Meaning Second Edition. Middlesex: Penguin Books Ltd. 
Nöth, Winfried. (1995). Handbook of Semiotics. USA: Indiana University Press

Wadison, Epi. (2012). Semantics and Pragmatics. Student's handbook

W. Deacon, Terrence. (2012). Memes as Signs in the Dynamic Logic of Semiosis: Molecular Science meets Computation Theory . Department of Anthropology and Neurosciences Program University of California, Berkeley

W. Kreidler, Charles. (2010). Introducing English Semantics. London and Newyork: Routledge

Collins, H. (2014). English Dictionary - Complete and Unabridged, 12th Edition

Ramirez, C. (2008). webcomic board. The comic was uploaded to deviant ART on .

Mann, C, W. (2016). Inquiry semantics : a functional semantics of natural language grammar, California : USA.

Baldwin, T. (2016). Lexical semantics introduction. Merlbourne University : Australia. 